\title{
Knowledge, attitude, practice, and self-efficacy of women regarding cervical cancer screening
}

\author{
Shahnaz Ghalavandi, Msc Student ${ }^{1}$, Alireza Heidarnia, PhD, Fatemeh Zarei, PhD', \\ Reza Beiranvand, $\mathrm{PhD}^{2}$

\begin{abstract}
${ }^{1}$ Department of Health Education \& Health Promotion, Faculty of Medical Sciences, Tarbiat Modares University; ${ }^{2}$ Department of Epidemiology \& Biostatistics, School of Public Health, Tehran University of Medical Sciences, Tehran, Iran
\end{abstract}

\section{Objective}

Iran has a low incidence of cervical cancer (CC). The country is introducing an organized screening system, including human papillomavirus screening. Studies show a high dropout rate among eligible women in continuing testing.

\section{Methods}

This descriptive-analytic study was part of the first phase of a clinical trial conducted on a random sample of 400 women aged 18-49 in Andimeshk City, Khuzestan Province, in 2020. The data collection tool consisted of a man-made questionnaire that included domains of demographic characteristics, knowledge, attitude, practice, and self-efficacy in the Pap smear test. The data were analyzed with Stata-16 using linear and logistic regression models.

Results

The mean knowledge, attitude, and self-efficacy scores were $6.80 \pm 2.33,34.99 \pm 4.32$, and $28.67 \pm 7.34$, respectively. In the multiple models, every unit increase in the knowledge or attitude scores raised the mean self-efficacy score by 1.04 and 0.48 , respectively $(P<0.001)$. Every unit increase in the knowledge and self-efficacy scores increased the chance of performing Pap smear 1.61 and 1.41 times, respectively $(P<0.001)$.

\section{Conclusion}

Given the association of women's knowledge and self-efficacy with practice in performing the Pap smear, it seems that an effective program promoting women's health behavior regarding CC screening would include applied education to raise community awareness and improve women's attitudes, self-efficacy, and practice.

Keywords: Knowledge; Attitude; Self efficacy; Papanicolaou test

\section{Introduction}

Cervical cancer (CC) is the 4th most common cancer among women globally. In 2018 alone, 570,000 new cases occurred, of which $7.5 \%$ led to cancer-related deaths. Annually, over 311,000 deaths due to CC occur globally, $85 \%$ of which take place in less developed communities [1]. In terms of health priority, Iran's CC epidemiology, both through the pathology-based cancer registry (ASR 2.2 per 100,000) [2] and population-based registries (6 per 100,000 in 2012) [2,3], demonstrates a low incidence but a high mortality rate (54\%) [2]. According to a World Health Organization (WHO) report, in 2018 breast cancer was the leading cause of cancer in Asia and the Middle Eastern region, followed by CC [4]. Based on the literature, the incidence of this type of cancer is 4.5 per
100,000 in Iran [5]. Every year, 1 of 123 women becomes afflicted with CC, and 9 of every 100,000 women die of it [6].

Received: 2020.08.09. Revised: 2020.10.07. Accepted: 2020.10.14. Corresponding author: Alireza Heidarnia, $\mathrm{PhD}$

Department of Health Education \& Health Promotion, Faculty of Medical Sciences, Tarbiat Modares University, Al Ahmad Street, Jalal, No. 7, Tehran 14115-331, Iran

E-mail: hidarnia@modares.ac.ir

https://orcid.org/0000-0003-1534-4757

Articles published in Obstet Gynecol Sci are open-access, distributed under the terms of the Creative Commons Attribution Non-Commercial License (http://creativecommons. org/licenses/by-nc/3.0/) which permits unrestricted non-commercial use, distribution, and reproduction in any medium, provided the original work is properly cited.

Copyright $\odot 2021$ Korean Society of Obstetrics and Gynecology 


\section{Obstetrics \& Gynecology Science}

Shahnaz Ghalavandi, et al. Knowledge, attitude, practice, and self-efficacy about Pap-test

According to estimates by the WHO, by 2030, CC will cause 474,000 deaths among women annually, and $95 \%$ of these deaths will occur in low- and middle-income countries [7].

CC screening (the Pap smear test) detects precancerous lesions at various stages to enable treatment. CC also develops relatively early and is one of the 3 most common cancers in most countries among women under 45 years, mainly from reproductive age [8]. Access to these preventive services is limited in developing countries, and CC is often not detected until its late stages [9]. Based on the literature, $60 \%$ of CCrelated deaths are preventable through Pap smear testing [10].

The current status of CC screening in Iran. By 2016, the Islamic Republic of Iran had implemented an opportunistic testing strategy (excluding cytology and testing) for CC screening (CCS) every 3 to 5 years for all women between 30 and 65 years of age, integrated into primary health care services [11]. At the end of 2016, Iran launched a specific health intervention package to combat non-communicable disease [12]. According to the updated national CCS protocol, all women between the ages of 30 and 59 are eligible for early diagnosis checkups, including history-taking and a general examination/observation every 5 years. General tests will be applied to women after 50 years, but the tests will be voluntary $[13,14]$.

All women who have had at least 1 instance of sexual intercourse are at risk of CC. This disease progresses slowly, and its early detection through Pap smear can prevent severe complications [15]. Nevertheless, past studies have indicated that in Iran, women do not take the Pap smear very seriously $[16,17]$. According to the literature, knowledge, attitude, and self-efficacy possibly affect women's practice toward Pap smear testing, and human behavior is influenced by various personal, cultural, and social factors. In other words, previous studies have shown that improvements in educational status not only significantly increase the knowledge of Pap smear test, but are also related to women's attitude and selfefficacy regarding the Pap smear test $[18,19]$. In addition, with strengthened positive attitude and increasing self-efficacy, the intention to perform Pap smear tests in women increases $[20,21]$. Thus, this study was conducted to determine the status of knowledge, attitude, practice, and self-efficacy and the probable mutual relationship between these factors in the women attending Andimeshk City's Comprehensive Health Centers and Health Bases in 2019.

\section{Materials and methods}

\section{Study design and inclusion criteria}

This descriptive-analytic study was conducted to determine the status of knowledge, attitude, practice, and self-efficacy related to Pap smear in Iranian women. It was part of the first phase of the clinical trial entitled "Design, Implementation, and Evaluation of the Impact of the Educational Program on Cervical Cancer Screening (Pap smears)." The study setting included the Comprehensive Health Centers and Health Bases in Andimeshk City, Khuzestan Province. The study was conducted in 2019, and sampling continued for the 2 weeks of Feb 4-19, 2020.

\section{Participants}

The participants of this study were 18-49-year-old women attending Comprehensive Health Centers and Health Bases under the coverage of those centers in Andimeshk City. Those who met the inclusion criteria were selected through stratified random sampling. First, a list of Andimeshk health centers and bases and the populations covered by them was obtained from the Human Resources Unit of the city's health network. There were 5 comprehensive health centers and 11 health bases. For the purposes of sampling, each center or base was considered as a stratum and the sample size was determined from each stratum by the proportion of the female population covered by that stratum. To randomize the samples, they were selected from those receiving health services from all health workers employed at the health centers. The health workers were trained to complete the questionnaire and obtain their consent. They were then told to perform sampling for 2 continuous weeks and to select the second person they visited after 9:30 am. This was done to collect normal samples, as those who visit health centers immediately after opening hours are usually people who are sensitive to their health, while those who visit in the late hours have socio-economic difficulties.

The inclusion criteria were as follows: married women aged 18-49 years (married at least once, regardless of their current marital status), Andimeshk residents, a basic level of literacy, having given written informed consent to participate in the study. The exclusion criteria were CC or other sexually transmitted diseases and unwillingness to participate in the study. 


\title{
Obstetrics \& Gynecology Science
}

\author{
Vol. 64, No. 2, 2021
}

\section{Variables}

The variables collected in this study were classified into 2 groups: the main variables and the modifiers (baseline characteristics). There were 4 main variables, namely, knowledge, attitude, self-efficacy, and practice regarding performing the Pap smear, in this study.

In terms of the operational definition of these 4 key components of our study, knowledge refers to participants' knowledge and understanding of CC screening, which will be measured by answering scale questions related to this concept. Attitude includes women's beliefs about CC screening, which will be measured by answering scale questions related to this concept. Self-efficacy includes the participant's understanding and confidence in their ability to perform CC screening, which will be measured by answering scale questions related to this concept. Finally, practice with respect to the intention of the participant to participate in CC screening is to be measured based on the answers to the scale questions related to this concept. The modifiers included educational status, age, occupation, current marital status, age at first sexual intercourse, economic status, husband's occupation, and history of performing the Pap smear test.

\section{Data collection tools}

The assessment tool was a man-made questionnaire for Pap smear screening comprising 5 sections. The first section consisted of demographic questions (Table 1). The knowledge domain had 13 questions with 3-item responses (correct, incorrect, don't know), such that correct answers received a score of 1 , incorrect and don't know a score of 0 . The attitude domain contained 12 questions scored on a 5-point Likert-type scale (completely uncertain, somewhat uncertain, no idea, somewhat certain, and completely certain). In the attitude and self-efficacy domains, the questions garnered scores between 1 and 5 depending on the responses. The practice domain comprised 4 yes/no questions scored 1 or 0 respectively.

The self-efficacy domain of this questionnaire is based on the questionnaire used by Fernández et al. [22] among Mexican-American women in 2009 (Supplementary Data 1), which was translated from English into Persian and its validity and reliability examined. To this end, we obtained permission from its creators, and after obtaining the guideline, forward-backward translation was performed. Two experts from the health domain separately translated the scales into
Persian. After an accurate review and cultural adaptation, minor modifications were made to the questionnaire. The 2 translated versions were then compared with each other, and the translated items were adjusted to match their English counterparts. The final version was then back-translated into English to compare and adapt it to the original version.

Eventually, the completed questionnaire (with 5 domains: demographic, knowledge, attitude, practice, and selfefficacy) was quantitatively and qualitatively examined for content validity. The scales were presented to 12 relevant specialists in CC screening, and their final opinions were obtained through an online expert panel meeting. Upon collecting their opinions, necessary changes were applied. We used a content validity ratio (CVR) and index to quantitatively examine content validity. To calculate the CVR we asked the experts to choose one of the following options with regard to the items of each scale: necessary, not necessary but useful, or not necessary. Cronbach's alpha coefficient was used

Table 1. Baseline characteristics of the subjects under study

\begin{tabular}{|c|c|c|}
\hline \multicolumn{2}{|l|}{ Variables } & \multirow{2}{*}{$\begin{array}{c}\text { Value } \\
32.97 \pm 5.98\end{array}$} \\
\hline Age $($ mean $\pm S D)$ & & \\
\hline \multirow[t]{2}{*}{ Marital status } & Married & $380(95.0)$ \\
\hline & Divorced & $20(5.0)$ \\
\hline \multirow[t]{4}{*}{ Educational status } & Primary school & $37(9.3)$ \\
\hline & Middle school & $111(27.7)$ \\
\hline & High school & $132(33.0)$ \\
\hline & Academic & $120(30.0)$ \\
\hline \multirow[t]{3}{*}{ Occupation } & Homemaker & $358(89.5)$ \\
\hline & Employee & $40(10.0)$ \\
\hline & Freelance & $2(0.5 .0)$ \\
\hline \multirow[t]{3}{*}{ Husband's occupation } & Employee & $116(29.0)$ \\
\hline & Freelance & $269(67.2)$ \\
\hline & Unemployed & $15(3.8)$ \\
\hline \multirow[t]{3}{*}{ Economic status } & $\begin{array}{l}\text { Expenditure less than } \\
\text { income }\end{array}$ & $132(33.0)$ \\
\hline & $\begin{array}{l}\text { Expenditure exceeding } \\
\text { income }\end{array}$ & $119(29.7)$ \\
\hline & $\begin{array}{l}\text { Expenditure equal to } \\
\text { income }\end{array}$ & $149(37.3)$ \\
\hline \multirow{2}{*}{$\begin{array}{l}\text { History of performing } \\
\text { the Pap smear }\end{array}$} & Yes & $229(58.6)$ \\
\hline & No & $162(41.4)$ \\
\hline
\end{tabular}

Values are presented as number (\%).

$\mathrm{SD}$, standard deviation. 


\section{Obstetrics \& Gynecology Science}

Shahnaz Ghalavandi, et al. Knowledge, attitude, practice, and self-efficacy about Pap-test

to evaluate internal consistency, and had the values of 0.81 , $0.79,0.85$, and 0.91 for the knowledge, attitude, self-effica$c y$, and practice domains, respectively.

\section{Sample size and data collection and completion}

After the women attending Andimeshk City's health centers were briefed on the study topic and goals, and considering the inclusion and exclusion criteria, they were invited to participate in the study. Those inclined to take part were requested to give written informed consent. Given the findings of Ghaoomi et al. [23] and using the following formula, $\alpha=0.05, \beta=0.2$, and $d=0.05$, a target sample size of 307 was calculated. Taking into account the possibility of $10 \%$ sample loss, we adopted an estimated sample size of 337 . Eventu- ally, to increase the accuracy of the study, a final sample size of 400 was considered.

$$
n=\frac{\left(Z_{1-\frac{\alpha}{2}}\right)^{2}(P(1-P))}{d^{2}}
$$

\section{Statistical analysis}

STATA-16 software was used to analyze the collected data. Descriptive statistical measures such as mean, standard deviation, and relative frequency percentage were used. Simple and multiple linear regression models were applied to examine the factors influencing knowledge, attitude, and selfefficacy, while simple and multiple logistic regression models were applied to examine the factors influencing practice. For

Table 2. The association between baseline characteristics and knowledge score regarding the Pap smear test in women attending Andimeshk's comprehensive health centers in 2019

\begin{tabular}{|c|c|c|c|c|c|}
\hline \multirow{2}{*}{\multicolumn{2}{|c|}{ Baseline characteristics }} & \multicolumn{2}{|l|}{ Crude $^{a)}$ model } & \multicolumn{2}{|c|}{ Adjusted $^{\text {b) }}$ model } \\
\hline & & \multirow{2}{*}{$\begin{array}{c}\text { B }^{\text {c) }}(\mathbf{9 5} \% \mathbf{C l}) \\
5.02(3.75,6.29)\end{array}$} & \multirow{2}{*}{$\begin{array}{l}\boldsymbol{P} \text {-value } \\
<0.001\end{array}$} & \multirow{2}{*}{$\frac{\mathrm{B}^{\mathrm{c})}(\mathbf{9 5 \%} \mathbf{C l})}{\text { Intercept }^{\mathrm{d})}}$} & \multirow[t]{2}{*}{$P$-value } \\
\hline Age & Reference & & & & \\
\hline & Increase per unit & $0.054(0.015,0.091)$ & 0.006 & $-0.007(-0.031,0.017)$ & 0.556 \\
\hline \multirow{2}{*}{$\begin{array}{l}\text { Age at first sexual } \\
\text { intercourse }\end{array}$} & Reference & $9.09(7.97,10.20)$ & $<0.001$ & Intercept ${ }^{\mathrm{d})}$ & \\
\hline & Increase per unit & $-0.04(-0.099,0.001)$ & 0.06 & $-0.01(-0.047,0.027)$ & 0.52 \\
\hline \multirow{2}{*}{$\begin{array}{l}\text { History of performing } \\
\text { the Pap smear }\end{array}$} & No (reference) & $5.61(5.28,5.94)$ & $<0.001$ & Intercept ${ }^{d)}$ & \\
\hline & Yes & $2.03(1.60,2.46)$ & $<0.001$ & $2.22(1.84,2.60)$ & $<0.001$ \\
\hline \multirow[t]{2}{*}{ Being married } & Married (reference) & $6.57(6.36,6.79)$ & $<0.001$ & Intercept $^{\text {d) }}$ & \\
\hline & Divorced & $4.42(3.46,5.38)$ & $<0.001$ & $5.64(5.01,6.27)$ & $<0.001$ \\
\hline \multirow[t]{4}{*}{ Educational status } & Primary school (reference) & $3.02(2.39,3.66)$ & $<0.001$ & Intercept $^{\text {d) }}$ & \\
\hline & Middle school & $3.74(3.01,4.47)$ & $<0.001$ & $3.52(2.70,4.33)$ & $<0.001$ \\
\hline & High school & $4.73(4.01,5.44)$ & $<0.001$ & $4.67(4.02,5.32)$ & $<0.001$ \\
\hline & Academic & $3.89(3.17,4.62)$ & $<0.001$ & $3.11(2.50,3.72)$ & $<0.001$ \\
\hline \multirow[t]{3}{*}{ Husband's occupation } & Unemployed (reference) & $4(2.87,5.12)$ & $<0.001$ & Intercept ${ }^{d)}$ & \\
\hline & Freelance & $2.55(1.40,3.73)$ & $<0.001$ & $3.48(2.56,4.40)$ & $<0.001$ \\
\hline & Employee & $3.72(2.53,4.91)$ & $<0.001$ & $2.52(1.52,3.52)$ & $<0.001$ \\
\hline \multirow[t]{3}{*}{ Economic status } & $\begin{array}{l}\text { Expenditure exceeding } \\
\text { income (reference) }\end{array}$ & $5.93(5.52,6.34)$ & $<0.001$ & Intercept ${ }^{\mathrm{d})}$ & \\
\hline & $\begin{array}{l}\text { Expenditure equal to } \\
\text { income }\end{array}$ & $1.33(0.78,1.88)$ & $<0.001$ & $0.78(0.31,1.25)$ & 0.001 \\
\hline & $\begin{array}{l}\text { Expenditure less than } \\
\text { income }\end{array}$ & $1.11(0.54,1.67)$ & $<0.001$ & $1.76(1.31,2.22)$ & $<0.001$ \\
\hline
\end{tabular}

$\mathrm{Cl}$, confidence interval.

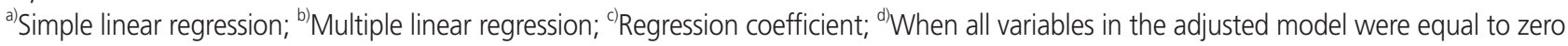
$(\mathrm{B}=4.21 ; 95 \% \mathrm{Cl}, 3.26,5.17$; and $P<0.001)$. 


\section{Obstetrics \& Gynecology Science}

Vol. 64, No. 2, 2021

the sake of the interpretability of the intercepts (a), continuous variables such as age were total-centered in the model. Qualitative variables were entered into the regression models as 2-dimensional or multi-dimensional variables to make the regression coefficients positive and interpretable. Those variables significant at a $P$-value of 0.05 in the simple regression models were entered into the multiple regression models. The level of error was considered to be 0.05 for all statistical analyses.

\section{Limitations}

Like any other study, this study had certain strengths and weaknesses. The relatively low response rate can be explained by the fact that data collection coincided with the coronavirus disease 2019 pandemic in Iran. Accordingly, we tried to complete the questionnaires over the phone.

\section{Results}

In this study, 400 women meeting the inclusion criteria with a mean age of $32.96 \pm 5.99$ years were studied. In terms of background characteristics, most participants were married, had high school education, were homemakers, had moder-

Table 3. The association between baseline characteristics and attitude scores regarding the Pap smear test in women attending Andimeshk's comprehensive health centers in 2019

\begin{tabular}{|c|c|c|c|c|c|}
\hline \multirow{2}{*}{\multicolumn{2}{|c|}{ Baseline characteristics }} & \multicolumn{2}{|c|}{ Crude $^{a)}$ model } & \multicolumn{2}{|c|}{ Adjusted $^{\text {b) }}$ model } \\
\hline & & \multirow{2}{*}{$\begin{array}{c}\text { B }^{\text {c) }}(\mathbf{9 5} \% \mathbf{C l}) \\
41.26(38.96,43.55)\end{array}$} & \multirow{2}{*}{$\begin{array}{l}P \text {-value } \\
<0.001\end{array}$} & \multirow{2}{*}{$\frac{\mathbf{B}^{\mathrm{c})}(\mathbf{9 5} \% \mathbf{C l})}{\text { |ntercept }^{\mathrm{d})}}$} & \multirow[t]{2}{*}{ P-value } \\
\hline Age & Reference & & & & \\
\hline & Increase per unit & $-0.19(-0.25,-0.12)$ & $<0.001$ & $-0.23(-0.30,-0.167)$ & $<0.001$ \\
\hline \multirow{2}{*}{$\begin{array}{l}\text { Age at first sexual } \\
\text { intercourse }\end{array}$} & Reference & $42.14(40.07,44.20)$ & $<0.001$ & Intercept $^{\mathrm{d})}$ & \\
\hline & Increase per unit & $-0.072(-0.16,0.02)$ & 0.069 & $-0.04(-0.148,0.05)$ & 0.5 \\
\hline \multirow{2}{*}{$\begin{array}{l}\text { History of performing } \\
\text { the Pap smear }\end{array}$} & No (reference) & $34.82(34.14,35.49)$ & $<0.001$ & Intercept $^{\mathrm{d})}$ & \\
\hline & Yes & $0.25(-0.65,1.15)$ & 0.585 & $0.83(-0.57,2.25)$ & 0.225 \\
\hline \multirow[t]{2}{*}{ Being married } & Married (reference) & $34.54(34.13,34.94)$ & $<0.001$ & Intercept ${ }^{\mathrm{d})}$ & \\
\hline & Divorced & $8.45(6.69,10.21)$ & $<0.001$ & $10.90(8.04,13.77)$ & $<0.001$ \\
\hline \multirow[t]{4}{*}{ Educational status } & Primary school (reference) & $34.64(33.27,36.02)$ & $<0.001$ & Intercept $^{\mathrm{d})}$ & \\
\hline & Middle school & $1.79(0.15,3.42)$ & 0.032 & $-0.79(-3.49,1.91)$ & 0.565 \\
\hline & High school & $0.16(-1.38,1.72)$ & 0.831 & $-1.92(-4.44,0.58)$ & 0.133 \\
\hline & Academic & $0.47(-1.10,2.04)$ & 0.555 & $3.29(1.19,5.40)$ & 0.002 \\
\hline \multirow[t]{3}{*}{ Husband's occupation } & Unemployed (reference) & $34(31.80,36.19)$ & $<0.001$ & Intercept ${ }^{\mathrm{d})}$ & \\
\hline & Freelance & $1.21(-1.04,3.47)$ & 0.601 & $3.53(0.71,6.34)$ & 0.014 \\
\hline & Employee & $0.62(-1.71,2.95)$ & 0.291 & $2.53(0.38,5.45)$ & $<0.001$ \\
\hline \multirow[t]{3}{*}{ Economic status } & $\begin{array}{l}\text { Expenditure exceeding } \\
\text { income (reference) }\end{array}$ & $35.79(34.95,36.62)$ & $<0.001$ & Intercept $^{\mathrm{d})}$ & \\
\hline & $\begin{array}{l}\text { Expenditure equal to } \\
\text { income }\end{array}$ & $-0.46(-1.55,0.62)$ & 0.404 & $-1.38(-2.70,-0.05)$ & 0.041 \\
\hline & $\begin{array}{l}\text { Expenditure less than } \\
\text { income }\end{array}$ & $-1.81(-2.93,-0.69)$ & 0.002 & $-1.25(-2.62,0.10)$ & 0.071 \\
\hline \multirow[t]{2}{*}{ Knowledge score } & Reference & $31.55(30.15,32.95)$ & $<0.001$ & Intercept ${ }^{\mathrm{d})}$ & \\
\hline & Increase per unit & $0.49(0.29,0.68)$ & $<0.001$ & $0.28(0.05,0.52)$ & 0.032 \\
\hline
\end{tabular}

$\mathrm{Cl}$, confidence interval.

${ }^{\text {a) }}$ Simple linear regression; ${ }^{\text {b) }}$ Multiple linear regression; ${ }^{\text {c}}$ Regression coefficient; ${ }^{d)}$ When all variables in the adjusted model were equal to zero $(\mathrm{B}=40.52 ; 95 \% \mathrm{Cl}, 37.39,43.64$; and $P<0.001)$. 


\section{Obstetrics \& Gynecology Science}

Shahnaz Ghalavandi, et al. Knowledge, attitude, practice, and self-efficacy about Pap-test

ate economic status (expenditure equal to income) and had a history of performing the Pap smear (Table 1).

The mean ( \pm standard deviation) scores of knowledge, attitude, and self-efficacy were $6.80 \pm 2.33,34.99 \pm 4.32$, and $28.67 \pm 7.34$, respectively. Simple and multiple analyses showed that being divorced, having a higher educational status, husband's occupation, having a history of performing the Pap smear test, and an average or good economic status had statistically significant associations with higher knowledge scores (Table 2). The simple analysis indicated that an increase in age, being divorced, educational status, good economic status, and a higher knowledge score were statisti- cally associated with the attitude score, while the multiple analysis showed that economic status was not significantly associated with the attitude score (Table 3).

Regarding the factors that influence self-efficacy, after adjustment for age, marital status, educational status, history of performing the Pap smear test, husband's occupation, and economic status, the simple and multiple analyses indicated that increases in the knowledge and attitude scores were significantly associated with the self-efficacy score (Table 4).

Upon examining the relationship between knowledge, attitude, and self-efficacy scores and the intention to perform the Pap smear test, the adjusted model showed that for

Table 4. The association between baseline characteristics and self-efficacy score regarding the Pap smear test in women attending Andimeshk's comprehensive health centers in 2019

\begin{tabular}{|c|c|c|c|c|c|}
\hline \multirow{2}{*}{\multicolumn{2}{|c|}{ Variables }} & \multicolumn{2}{|c|}{ Crude $^{\text {a) }}$ model } & \multicolumn{2}{|c|}{ Adjusted $^{b, c)}$ model } \\
\hline & & \multirow{2}{*}{$\begin{array}{c}\mathbf{B}^{\mathrm{d})}(\mathbf{9 5 \%} \mathrm{Cl}) \\
18.89(16.66,21.12)\end{array}$} & \multirow{2}{*}{$\begin{array}{l}\boldsymbol{P} \text {-value } \\
<0.001\end{array}$} & \multirow{2}{*}{$\begin{array}{c}\mathbf{B}^{\mathrm{d})}(\mathbf{9 5} \% \mathbf{C I}) \\
\text { (ntercept }^{\mathrm{e})}\end{array}$} & \multirow[t]{2}{*}{$P$-value } \\
\hline Knowledge score & Reference & & & & \\
\hline & Increase per unit & $1.39(1.09,1.70)$ & $<0.001$ & $1.54(1.22,1.85)$ & $<0.001$ \\
\hline \multirow[t]{2}{*}{ Attitude score } & Reference & $7.55(2.76,12.34)$ & 0.002 & Intercept $^{\mathrm{e})}$ & \\
\hline & Increase per unit & $1.03(0.89,1.17)$ & $<0.001$ & $0.48(0.37,0.58)$ & $<0.001$ \\
\hline \multirow[t]{2}{*}{ Age } & Reference & $35.25(31.26,39.24)$ & $<0.001$ & Intercept $^{\mathrm{e})}$ & \\
\hline & Increase per unit & $-0.19(-0.31,-0.08)$ & 0.001 & $-0.07(-0.14,-0.003)$ & 0.039 \\
\hline \multirow{2}{*}{$\begin{array}{l}\text { Age at first sexual } \\
\text { intercourse }\end{array}$} & Reference & $45.36(42.06,48.66)$ & $<0.001$ & Intercept $^{\mathrm{e})}$ & \\
\hline & Increase per unit & $-0.13(-0.28,0.01)$ & 0.061 & $-0.03(-0.153,0.09)$ & 0.63 \\
\hline \multirow{2}{*}{$\begin{array}{l}\text { History of performing } \\
\text { the Pap smear }\end{array}$} & No (reference) & $26.5(25.38,27.61)$ & $<0.001$ & Intercept ${ }^{\mathrm{e}}$ & \\
\hline & Yes & $3.88(2.40,5.36)$ & $<0.001$ & $-1.82(-3.21,-0.43)$ & $<0.001$ \\
\hline \multirow[t]{2}{*}{ Being married } & Married (reference) & $28.04(27.33,28.75)$ & $<0.001$ & Intercept $^{\mathrm{e})}$ & \\
\hline & Divorced & $11.95(8.86,15.05)$ & $<0.001$ & $6.04(3.31,8.77)$ & $<0.001$ \\
\hline \multirow[t]{2}{*}{ Educational status } & Primary school (reference) & $32.63(31.07,34.19)$ & $<0.001$ & Intercept ${ }^{\mathrm{e})}$ & \\
\hline & Increase per level & $2.10(1.36,2.84)$ & $<0.001$ & $4.33(3.73,4.93)$ & $<0.001^{d)}$ \\
\hline \multirow[t]{3}{*}{ Husband's occupation } & Unemployed (reference) & $21(17.47,24.52)$ & $<0.001$ & Intercept ${ }^{\mathrm{e})}$ & \\
\hline & Freelance & $9.27(5.64,8.96)$ & $<0.001$ & $11.60(9.37,13.83)$ & $<0.001$ \\
\hline & Employee & $5.21(1.46,8.96)$ & 0.007 & $6.57(4.21,8.95)$ & $<0.001$ \\
\hline \multirow[t]{3}{*}{ Economic status } & $\begin{array}{l}\text { Expenditure exceeding } \\
\text { income (reference) }\end{array}$ & $28.04(26.60,29.47)$ & $<0.001$ & Intercept ${ }^{\mathrm{e})}$ & \\
\hline & $\begin{array}{l}\text { Expenditure equal to } \\
\text { income }\end{array}$ & $2.17(0.32,4.02)$ & 0.021 & $5.83(4.67,6.99)$ & $<0.001$ \\
\hline & $\begin{array}{l}\text { Expenditure less than } \\
\text { income }\end{array}$ & $-0.63(-2.53,1.25)$ & 0.508 & $1.77(0.71,2.83)$ & 0.001 \\
\hline
\end{tabular}

$\mathrm{Cl}$, confidence interval.

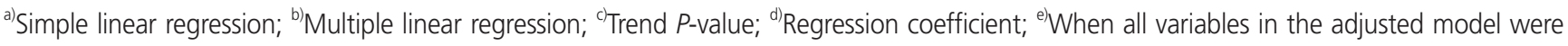
equal to zero $(B=-0.43 ; 95 \% C l,-5.82,4.95 ; P=0.875)$. 


\title{
Obstetrics \& Gynecology Science
}

\author{
Vol. 64, No. 2, 2021
}

every unit increase in knowledge, attitude, and self-efficacy scores, the chance of performing the Pap smear test increased by 1.61, 1.02, and 1.41, respectively. The increased chance related to the associations between increased knowledge and self-efficacy scores and the intention to perform the Pap smear test was statistically significant (Table 5).

\section{Discussion}

We found that an increase in the level of knowledge and attitude among women regarding the Pap smear test raises their self-efficacy. The first and foremost step in health education is to educate individuals so as to create awareness and bring about behavior change, as it is the association between knowledge and behavior that changes attitudes by inculcating knowledge that might lead to behavior change. According to the results of the simple analysis, for every unit increase in the knowledge score, the chance of performing the Pap smear test increased by 1.07 times, though this association was not statistically significant $(P=0.212)$. On the other hand, for every unit increase in the attitude and selfefficacy scores, the chances of performing the Pap smear test increased by 1.21 and 1.30 times, both of which were statistically significant $(P<0.001)$. Upon adjusting for the effect of each of these factors, the results indicated that for every unit increase in knowledge and self-efficacy scores, the chances of performing the Pap smear test increased by 1.61 and 1.41 times, which increases were statistically significant $(P<0.001)$, while no significant association was observed between an increased attitude score and the chance of performing the test $(P=0.736)$. These findings are consistent with those of other studies [18,20,24]. Nevertheless, in Mings and Soto Mas [25] study, in which the target population was homeless women, no significant association was observed between knowledge and attitude with performing the Pap smear test, a finding that is inconsistent with ours. This inconsistency may be attributed to the differences in target populations between the 2 studies.

Based on our results, upon adjusting for the effects of other influential factors, for every unit increase in the knowledge score, the self-efficacy score increased by 1.54. Moreover, after adjusting for other influential factors, for every unit increase in the attitude score, the self-efficacy score increased by 0.48 , which was statistically significant $(P<0.001)$. Several studies [26-28] have shown that educational interventions aimed at raising awareness and attitude sustainably increase the level of self-efficacy, which is consistent with our findings. Bossard and Song [19] observed that the level of awareness was not significantly associated with individuals' self-efficacy on performing the Pap smear, a finding inconsistent with ours. This inconsistency may be attributed to their population under study, which consisted of immigrant women who had volunteered to participate in the study. Usually, those who volunteer in research studies have different levels of knowledge, attitude, and self-efficacy from the general population (selection bias; volunteer bias).

In this study, a rise in educational status was not only significantly associated with an increase in knowledge of the Pap smear test $(P<0.001)$, but was also associated with the attitude and self-efficacy of women toward the Pap smear, such that the mean attitude score of individuals with academic education was 3.29 higher than those with primary education. For every increase in educational grade, the mean self-efficacy score increased by 4.33 scores, which was statistically significant $(P<0.001)$. Morowati-sharifabad et al. [29] indicated that individuals with bachelor's and higher degrees were 2.58 times more likely than those with high school

Table 5. The association between knowledge, attitude, and self-efficacy scores on the intention to perform the Pap smear test in women attending Andimeshk's comprehensive health centers in 2019

\begin{tabular}{|c|c|c|c|c|}
\hline \multirow{2}{*}{ Variables } & \multicolumn{2}{|c|}{ Crude $^{a)}$ model } & \multicolumn{2}{|c|}{ Adjusted $^{\text {b) }}$ model } \\
\hline & OR $(95 \% \mathrm{Cl})$ & $P$-value & OR $(95 \% \mathrm{Cl})$ & $P$-value \\
\hline Knowledge & $1.07(0.95,1.20)$ & 0.212 & $1.61(1.44,1.77)$ & $<0.001$ \\
\hline Attitude & $1.21(1.12,1.31)$ & $<0.001$ & $1.02(0.90,1.14)$ & 0.736 \\
\hline Self-efficacy & $1.30(1.21,1.39)$ & $<0.001$ & $1.41(1.28,1.56)$ & $<0.001$ \\
\hline
\end{tabular}

$\mathrm{OR}$, odds ratio; $\mathrm{Cl}$, confidence interval.

${ }^{\text {a) }}$ Simple logistic regression; ${ }^{\text {b) }}$ Multiple logistic regression. 


\section{Obstetrics \& Gynecology Science}

Shahnaz Ghalavandi, et al. Knowledge, attitude, practice, and self-efficacy about Pap-test

education or less to perform the Pap smear test. This finding is consistent with our findings on the effect of higher educational status on self-efficacy in performing the Pap smear test [29]. Tilahun et al. [24] also achieved results similar to ours. Some other studies $[30,31]$ have reported no significant association between educational status and knowledge and practice in the Pap smear test in individuals. Although we did not confirm their findings, this difference may be due to the lack of adjustment of the effect of other variables in the aforementioned studies.

In conclusion, there is a positive relationship between knowledge, attitude, self-efficacy, and women's practice with regard to performing the Pap smear test, which is a widely accepted common test for the early detection and screening of CC. This study was part of the first phase of a clinical trial aimed at determining the current educational status and needs assessment of knowledge, attitude, self-efficacy, and practice regarding CC screening among women attending comprehensive health centers. Thus, it seems that an effective educational plan to promote women's health behavior toward CC screening would be to offer sufficient applied education to raise community awareness, which in turn would improve women's attitude and self-efficacy, eventually increasing their practice of the Pap smear test. This requires the development of organized educational programs based on theories of behavior change. Although the use of modern training techniques to promote CC prevention and Pap smear testing is recommended, the identification of sociocultural and economic factors, as well as policies and laws affecting women's behavioral intent to receive Pap smear tests is a priority before deciding any program training or making a training method choice. Further population-based studies aimed at determining the factors influencing community health behavior can guide health education planners and policymakers in planning appropriate health education programs.

\section{Acknowledgments}

We would like to extend our sincere gratitude to the all participants in this study. Special thank to one of participant who died in order to Covid-19. Furthermore, we appreciate the research deputy support in Faculty of Medical sciences, Thrabiat Modares University.

\section{Conflict of interest}

No potential conflict of interest relevant to this article was reported.

\section{Ethical approval}

This article is part of a thesis approved by Tarbiat Modares University's Faculty of Medicine registered under ethical code No. IR.MODARES.REC.1398.200.

\section{Patient consent}

In this study, informed consent was received from all the participants.

\section{Funding information}

None.

\section{Supplementary material}

Supplementary Data 1 associated with this article can be found online at https://doi.org/10.5468/ogs.20236.

\section{REFERENCES}

1. World Health Organization. Human papillomavirus (HPV) and cervical cancer [Internet]. Geneva: World Health Organization; c2019 [cited 2020 Nov 11]. Available from: https://www.who.int/news-room/fact-sheets/detail/ human-papillomavirus-(hpv)-and-cervical-cancer.

2. Khorasanizadeh F, Hassanloo J, Khaksar N, Mohammad Taheri S, Marzaban M, Rashidi B, et al. Epidemiology of cervical cancer and human papilloma virus infection among Iranian women - analyses of national data and systematic review of the literature. Gynecol Oncol 2013;128:277-81.

3. Majidi A, Ghiasvand R, Hadji M, Nahvijou A, Mousavi AS, Pakgohar $M$, et al. Priority setting for improvement 


\title{
Obstetrics \& Gynecology Science
}

\author{
Vol. 64, No. 2, 2021
}

of cervical cancer prevention in Iran. Int J Health Policy Manag 2015;5:225-32.

4. Bray F, Ferlay J, Soerjomataram I, Siegel RL, Torre LA, Jemal A. Global cancer statistics 2018: GLOBOCAN estimates of incidence and mortality worldwide for 36 cancers in 185 countries. CA Cancer J Clin 2018;68:394424.

5. Farajzadegan Z, Nourbakhsh SF, Mostajeran M, Loghmani A. Cervical cancer screening status in 35 to 60 year-old women in Isfahan, Iran. Majallahi Danishkadahi Pizishkii Isfahan 2012;208:1542.

6. Azizi F, Hatami H, Janghorbani M. Epidemiology and control of common diseases in Iran. Tehran: Eshtiagh Publications; 2000.

7. World Health Organization. Information centre on HPV and cervical cancer (HPV Information Centre): summary report on HPV and cervical cancer statistics in South Africa [Internet]. Geneva: World Health Organization; c2013 [cited 2013 Jun 27]. Available from: https://www. afro.who.int/fr/node/12184.

8. Ouh YT, Lee JK. Proposal for cervical cancer screening in the era of HPV vaccination. Obstet Gynecol Sci 2018;61:298-308.

9. Gupta R, Gupta S, Mehrotra R, Sodhani P. Cervical cancer screening in resource-constrained countries: current status and future directions. Asian Pac J Cancer Prev 2017;18:1461-7.

10. Mohebi S, Sharifirad G, Gharlipour Z, Kamran A. The study of Pap smear conduction and its related factors based on health belief model in women referring to health care centers in Qom during 2014. J Educ Community Health 2016;2:25-33.

11. World Health Organization. Global Health Observatory data repository, cervical cancer screening response by country [Internet]. Geneva: World Health Organization; c2020 [cited 2020 May 12]. Available from: https://apps. who.int/gho/data/view.main.UHCCERVICALCANCERv.

12. World Health Organization. Islamic Republic of Iran on a fast-track to beating noncommunicable diseases [Internet]. Geneva: World Health Organization; c2017 [cited 2017 Jun 20]. Available from: https://www.who. int/news-room/feature-stories/detail/islamic-republicof-iran-on-a-fast-track-to-beating-noncommunicablediseases.

13. The Ministry of Health of Iran. NCD PEN guideline,
IRAPEN, guideline for midwives. Tehran; The Ministry of Health of Iran; 2016.

14. The Ministry of Health and Medical Education of Iran DfPH. Integrated package of Iran for essential needs for NCD, protocol for breast and cervical cancer screening. Tehran; The Ministry of Health and Medical Education of Iran DfPH: 2016.

15. Kosha AS. A set of essential interventions non-communicable diseases in the primary health care system of Iran, IraPEN. 1th ed. Tehran: Mojasameh Publisher; 2017.

16. Khezeli M, Dehdari T. Knowledge, attitude and practice of female employees of health network in Guilan-Gharb county about cervical cancer and Pap smear. Prev Care Nurs Midwifery J 2012;1:43-50.

17. Rezaie Chamani S, Alizadeh M, Charandabi S, Kamalifard M. Knowledge, attitudes and practice about Pap smear among women reffering to a public hospital. J Family Reprod Health 2012;6:177-82.

18. Ijezie $A E$, Johnson OE. Knowledge of cervical cancer and the uptake of the Papanicolaou smear test among public secondary school teachers in Akwa Ibom State, Nigeria. Niger Med J 2019;60:245-51.

19. Bossard K, Song Y. The impact of perceived barriers on self-efficacy for HPV preventive behavior. Asian Pac J Cancer Prev 2018;19:983-8.

20. Miri MR, Moodi M, Sharif-Zadeh GR, Malaki Moghadam $H$, Miri M, Norozi E. Cognitive predictors of cervical cancer screening's stages of change among sample of Iranian women health volunteers: a path analysis. PLoS One 2018;13:e0193638.

21. Ahmed NU, Rojas P, Degarege A. Knowledge of cervical cancer and adherence to Pap smear screening test among female university students in a multiethnic institution, USA. J Natl Med Assoc 2020;112:300-7.

22. Fernández ME, Diamond PM, Rakowski W, Gonzales A, Tortolero-Luna G, Williams J, et al. Development and validation of a cervical cancer screening self-efficacy scale for low-income Mexican American women. Cancer Epidemiol Biomarkers Prev 2009;18:866-75.

23. Ghaoomi M, Aminimoghaddam S, Safari H, Mahmoudzadeh A. Awareness and practice of cervical cancer and Pap smear testing in a teaching hospital in Tehran. Tehran Univ Med J 2016;74:183-9.

24. Tilahun T, Tulu T, Dechasa W. Knowledge, attitude and 


\section{Obstetrics \& Gynecology Science}

Shahnaz Ghalavandi, et al. Knowledge, attitude, practice, and self-efficacy about Pap-test

practice of cervical cancer screening and associated factors amongst female students at Wollega University, western Ethiopia. BMC Res Notes 2019;12:518.

25. Mings J, Soto Mas F. Barriers to Pap smear among homeless women at albuquerque healthcare for the homeless. J Community Health 2019;44:1185-92.

26. Hoque ME, Ghuman S, Coopoosmay R, Van Hal G. Cervical cancer screening among university students in South Africa: a theory based study. PLoS One 2014;9:e111557.

27. Kim K, Xue QL, Walton-Moss B, Nolan MT, Han HR. Decisional balance and self-efficacy mediate the association among provider advice, health literacy and cervical cancer screening. Eur J Oncol Nurs 2018;32:55-62.

28. Tiraki Z, Yılmaz M. Cervical cancer knowledge, selfefficacy, and health literacy levels of married women. J
Cancer Educ 2018;33:1270-8.

29. Morowati-sharifabad MA, Vardanjani ZM, Raiisi Z, Mohammad Y. Predictors of Pap smear test based on protection motivation theory among women of shahreekord. J Tolooebehdasht 2018;17:43-55.

30. Heena H, Durrani S, AlFayyad I, Riaz M, Tabasim R, Parvez $G$, et al. Knowledge, attitudes, and practices towards cervical cancer and screening amongst female healthcare professionals: a cross-sectional study. J Oncol 2019;2019:5423130.

31. Hirani S, Khana S, Akram S, Virji SN, Shaikh PA, Naeem $\mathrm{E}$, et al. Knowledge, awareness, and practices of cervical cancer, its risk factors, screening, and prevention among women in Karachi, Pakistan. Eur J Cancer Prev Forthcoming 2021;30:97-102. 